\title{
Long-term outcome after surgical repair of anomalous origin of the left coronary artery from the pulmonary artery: 24 years of experience
}

\author{
Joanna Kwiatkowska1, Agnieszka Herrador Rey ${ }^{1}$, Jarosław Meyer-Szary'1, Karolina Dorniak², \\ Katarzyna Ostrowska³, Anna Wałdoch¹, Dariusz Kozłowski ${ }^{4}$, Alicja Dąbrowska-Kugacka ${ }^{4}$ \\ 1 Department of Pediatric Cardiology and Congenital Heart Defects, Medical University of Gdańsk, Gdańsk, Poland \\ 2 Department of Noninvasive Cardiac Diagnostics, Medical University of Gdańsk, Gdańsk, Poland \\ 3 Department of Cardiology, Polish Mother's Memorial Hospital, Research Institute, Łódź, Poland \\ 4 Department of Cardiology and Electrotherapy, Medical University of Gdańsk, Gdańsk, Poland
}

Correspondence to: Joanna Kwiatkowska, MD, PhD, Department of Pediatric Cardiology and Congenital Heart Defects, Medical University of Gdańsk, ul. Dębinki 7, 80-210 Gdańsk Poland, phone: +48583492870 , email: joannak@gumed.edu.pl Received: February19, 2019. Revision accepted: April 24, 2019. Published online: April 29, 2019. Kardiol Pol. 2019; 77 (7-8): 716-718 doi:10.33963/KP.14816

Copyright by the Author(s), 2019
Introduction Anomalous left coronary artery from the pulmonary artery (ALCAPA), also known as Bland-White-Garland syndrome, is a rare congenital anomaly (approximately 2.3 per 10000 live births), ${ }^{1,2}$ resulting in retrograde flow from the right coronary artery through natural collaterals to the main pulmonary artery. This causes extensive ischemia, left ventricular (LV) dysfunction, mitral valve insufficiency, and heart failure within the first weeks of life..$^{3-5}$ In untreated cases, the mortality rate is as high as $90 \%$ in the first year. ${ }^{6}$

Due to the improvement of surgical management and postoperative care over the last 30 years, the mortality rate has decreased to $5 \% .{ }^{7,8}$ However, the evaluation of outcomes is limited by small cohorts and relatively short follow-up in the published series. We present a retrospective, longitudinal study of patients with ALCAPA who underwent surgery. The aim of this study was to show clinical details, variations in the surgical technique, and postoperative long-term follow-up.

Methods Medical records of 24 patients with ALCAPA who underwent surgery between 1991 and 2014 were reviewed. Patients were invited to our institution and the data were collected prospectively according to the study protocol. Two patients did not respond. Additionally, 2 patients died during the interim period. Therefore, out of 24 patients who initially underwent surgery, the retrospective cohort encompassed 22 patients, and the prospective cohort, 20 patients (all were at least 1 year after surgery at inclusion).

The data included preoperative details, surgical procedure, as well as clinical and echocardiographic follow-up. The study was approved by the local institutional ethics committee.

Statistical analysis Statistical analyses were performed using Wizard Pro 1.9.13 (Evan Miller, Chicago, Illinois, United States). Categorical variables were expressed as count (n) and percentages. Continuous variables were expressed as mean (SD) or median (minimum - maximum), depending on the distribution. Normality of the distribution was tested using the Shapiro-Wilk test. The paired $t$ test and Wilcoxon signed-rank test were used for repeated measures, while the $t$ test and the MannWhitney test were used for other cases. For multiple comparisons, proper analysis of variance or the Friedman test was used. Categorical data were compared using the $X^{2}$, McNemar, and Stuart-Maxwell tests for assessing changes over time. A P value of less than 0.05 was considered significant.

Results and discussion Detailed preoperative characteristics are summarized in Supplementary material, Table S1. Suspected pneumonia 


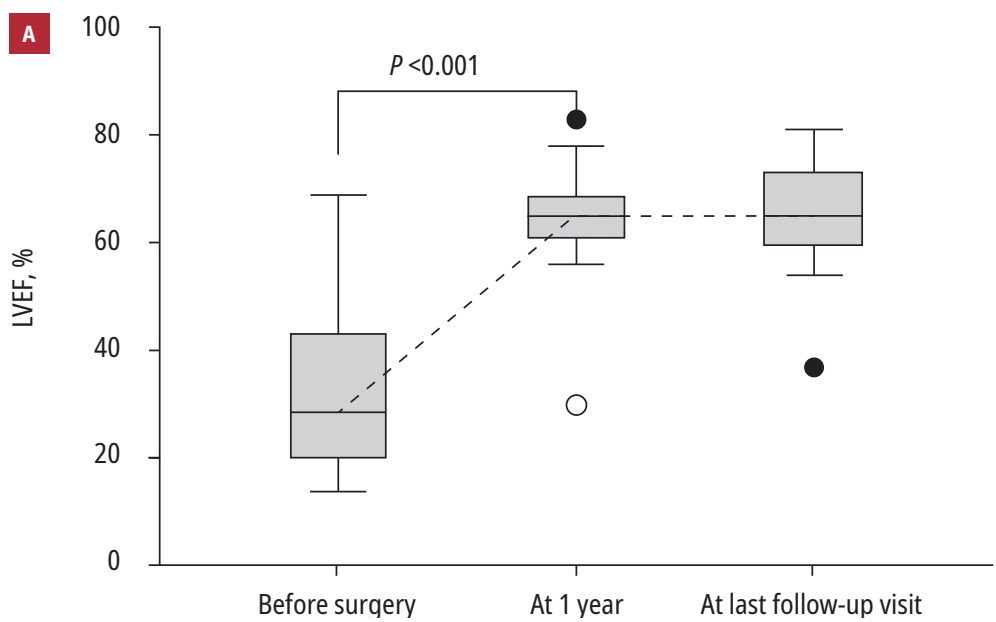

B

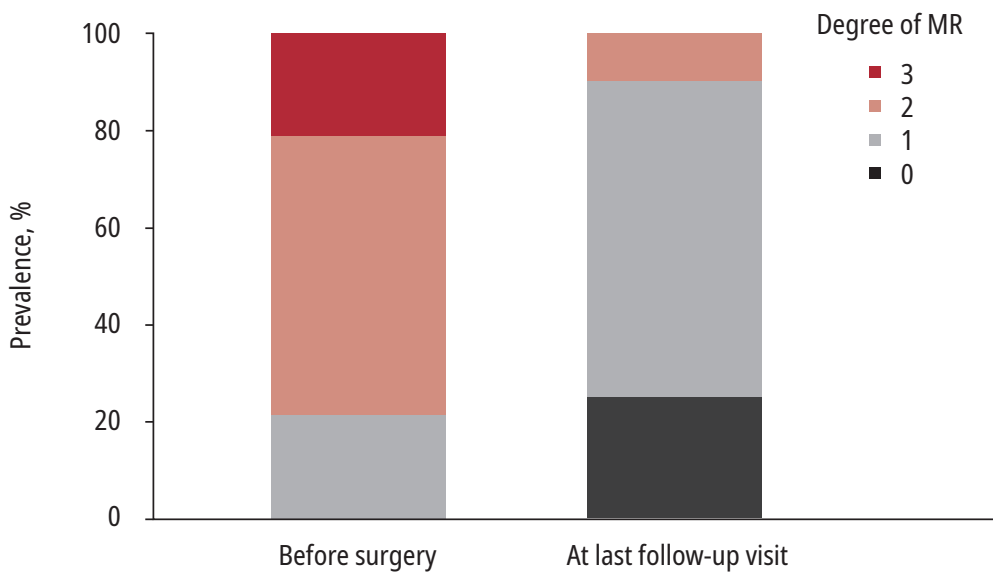

FIGURE 1 Long-term follow-up; A - changes in left ventricular ejection fraction (LVEF); full circles indicate an outlier and empty circles, extreme outliers; $\mathbf{B}$ - changes in the degree of mitral regurgitation (MR)
Long-term follow-up data (range, 1-23 years; mean, 13 years) were available for 20 patients (Supplementary material, Table S4). One of the 20 patients $(5 \%)$ died due to arrhythmia (documented ventricular fibrillation) at the age of 21 years. Based on the medical history, the patient had normal LV function and no symptoms. At the last follow-up, 15 of the 20 patients (75\%) were asymptomatic (New York Heart Association [NYHA] functional class I) and 5 of the 20 patients $(15 \%)$ were in NYHA class II. Patients who underwent the Takeuchi repair differed from the reimplantation group (NYHA class II in 3 of the 4 patients [75\%] vs 2 of the 16 patients [13\%]), although they were also older (24.8 years vs 13.2 years, $P=0.01$ ) and had longer follow-up (20.8 years vs 10.5 years, $P=0.02$ ).

Left ventricular function improved significantly at 1 year $(P<0.001)$. There was no difference between LV ejection fraction (LVEF) at 1 year and at the last visit $(P=0.97)$ in survivors (FIGURE 1A). Improvement of the mitral valve function was observed: moderate MR was present in 2 patients, and mild or no improvement in the remaining patients $(P<0.001$; Figure 1B). One of the 4 patients (25\%) who underwent the Takeuchi repair presented with pulmonary stenosis and baffle leak, which required reoperation at the age of 24 years. One of the 4 patients (25\%) after Takeuchi repair and 1 of the 18 patients (5.5\%) after coronary reimplantation developed pulmonary regurgitation, but none of them required reoperation.

Life-long prognosis for the treated patients remains uncertain. ${ }^{9}$ In the literature, 2 types of ALCAPA are distinguished: infant-type and adult-type. Our patients mainly had infant-type ALCAPA, which is in line with the reports of other authors. ${ }^{5,10}$ Despite suggestive clinical symptoms and a characteristic echocardiographic image of ALCAPA, preoperative angiography was performed in the majority of our patients (95\%). At present, some authors discredit the need for angiography in severely ill infants, ${ }^{11}$ but these patients require a rapid and accurate diagnosis, which may be impossible with noninvasive diagnostic tools.' Continuous advancements in computed tomography and magnetic resonance imaging may alleviate the need for angiography in the future.

Currently, reimplantation of the left coronary artery to the aortic root represents the most beneficial surgical technique. In our group, 4 children were operated on using the Takeuchi repair due to suboptimal anatomy. There were no differences in LVEF, LV end-diastolic diameter, and mitral or pulmonary valve function between the groups, although 1 patient (25\%) after the repair developed pulmonary stenosis and baffle leak, which required reoperation. Ginde et $\mathrm{al}^{12}$ summarized long-term results of the Takeuchi procedure in their case series. Survival was comparable with that after direct reimplantation. 
Baffle leak (27\% of patients) and supravalvular main pulmonary artery stenosis ( $24 \%$ of patients) were the most common complications of the Takeuchi repair.

Both LVEF and LV end-diastolic diameter improved over time and were within the normal range in the majority of our patients. The greatest improvement of these parameters was observed at 1 year after surgery. Some authors suggest that this may result from restored blood flow to the previously hibernated myocardium. ${ }^{3,13}$ Mitral valve function also improved, and no patient required mitral valve repair. However, surgical interventions for severe MR in long-term follow-up of patients with ALCAPA were described. ${ }^{13}$

One patient in our group died suddenly almost 21 years after treatment. This case suggests that the long-term postoperative prognosis of ALCAPA is uncertain. Ischemia may eventually cause irreversible injury, and nonsustained ventricular tachycardia was observed in patients with ALCAPA. ${ }^{14}$ This indicates an arrhythmogenic potential of the postischemic tissue. Whether it increases the risk of sudden death in these patients merits further research.

Interestingly, women prevailed in our group, which was also noticeable in some of the previous studies. ${ }^{3,13}$ Until recently, ALCAPA was believed to be equally prevalent in both sexes. This issue requires further research.

The limitation of our study is the small number of patients, although considering that ALCA$\mathrm{PA}$ is rare and the follow-up is long, this is a rather typical cohort size.

To summarize, ALCAPA repair using current surgical techniques provides excellent outcomes in the majority of patients. Despite very low early and late mortality rates, the long-term prognosis is unclear. Scars and perfusion deficits may be underestimated by standard echocardiography. Therefore, we believe that lifelong surveillance of these patients is necessary. The role of advanced imaging techniques in this population remains to be elucidated.

\section{SUPPLEMENTARY MATERIAL}

Supplementary material is available at www.mp.pl/kardiologiapolska.

\section{ARTICLE INFORMATION}

\section{CONFLICT OF INTEREST None declared.}

OPEN ACCESS This is an Open Access article distributed under the terms of the Creative Commons Attribution-NonCommercial-NoDerivatives 4.0 International License (CC BY-NC-ND 4.0), allowing third parties to download articles and share them with others, provided the original work is properly cited, not changed in any way, distributed under the same license, and used for noncommercial purposes only. For commercial use, please contact the journal office at kardiologiapolska@ptkardio.pl.

HOW TO CITE Kwiatkowska J, Herrador Rey A, Meyer-Szary], et al. Long-term outcome after surgical repair of anomalous origin of the left coronary artery from the pulmonary artery: 24 years of experience. Kardiol Pol. 2019; 77: 716-718. doi:10.33963/KP.14816

\section{REFERENCES}

1 Brotherton H, Philip RK. Anomalous left coronary artery from pulmonary artery (ALCAPA) in infants: a 5-year review in a defined birth cohort. Eur J Pediatr Suppl. 2008; 167: 43-46.

2 Werner B, Wróblewska-Kałuzewska M, Pleskot M, et al. Anomalies of the coronary arteries in children. Med Sci Monit. 2001; 7: 1285-1291.

3 Neumann A, Sarikouch S, Bobylev D, et al. Long-term results after repair of anomalous origin of left coronary artery from the pulmonary artery: Takeuchi repair versus coronary transfer. Eur J Cardiothorac Surg. 2017; 51: 308-315.

4 Weigand J1, Marshall CD, Bacha EA, et al. Repair of anomalous left coronary artery from the pulmonary artery in the modern era: preoperative predictors of immediate postoperative outcomes and long term cardiac follow-up. Pediatr Cardiol. 2015; 36: 489-497.

5 Stańko A, Kwiatkowska J, Meyer-Szary J. Anomalous origin of the left coronary artery from pulmonary artery as an example of myocardial infarction in children. [in Polish]. Pediatr Pol. 2016; 6: 581-586.

6 Rodriguez-Gonzalez M, Tirado AM, Hosseinpour R, de Soto JS. Anomalous origin of the left coronary artery from the pulmonary artery: diagnoses and surgical results in 12 pediatric patients. Tex Heart Inst J. 2015; 42: 350-356.

7 0jala T, Salminen J, Happonen JM, et al. Excellent functional result in children after correction of anomalous origin of left coronary artery from the pulmonary artery - a population-based complete follow-up study. Interact Cardiovasc Thorac Surg. 2010; 10: 70-75

8 Muzaffar T, Ganie, Swamy SG, Wani N. The surgical outcome of anomalous origin of the left coronary artery from the pulmonary artery. Int Cardiovasc Res J. 2014; 8: 57-60.

9 Alexi-Meskishvili V, Nasseri BA, Nordmeyer S, et al. Repair of anomalous origin of the left coronary artery from the pulmonary artery in infants and children. J Thorac Cardiovasc Surg. 2011; 142: 868-874.

10 Tedla MG, Worku DK. Anomalous left coronary artery from the pulmonary artery: mini-review. ARC J Cardiol. 2017; 3: 13-16.

11 Cohen MS, Herlong RJ, Silverman NH. Echocardiographic imaging of anomalous origin of the coronary arteries. Cardiol Young. 2010; 20 Suppl 3: 26-34.

12 Ginde S, Earing MG, Bartz PJ, et al. Late complications after Takeuchi repair of anomalous left coronary artery from the pulmonary artery: case series and review of literature. Pediatr Cardiol. 2012; 33: 1115-1123.

13 Kudumula V, Mehta C, Stumper 0, et al. Twenty-year outcome of anomalous origin of left coronary artery from pulmonary artery: management of mitral regurgitation. Ann Thorac Surg. 2014; 97: 938-944.

14 Parizek P, Haman L, Harrer J, et al. Bland-White-Garland syndrome in adults: sudden cardiac death as a first symptom and long-term follow-up after successful resuscitation and surgery. Europace. 2010; 12: 1338-1340. 